\title{
CARCINOMA OF CAECUM PRESENTING AS MEGA INTUSSUSCEPTION AND RECTAL MASS
}

\author{
M. Jawaid Rajput, A. Sattar Memon and Adeel Hamad Memon
}

\begin{abstract}
Carcinoma of colon and rectum are second commonest cancer cause of death in United Kingdom. Because, right colon has a large caliber, a thin and distensible wall and faecal content is fluid, so, carcinoma of right colon may attain a large size before it gives specific symptoms. Any complication like acute appendicitis or intussusception may draw early attention, when curative resection is possible. In this report, an unusual presentation of carcinoma of caecum is reported.
\end{abstract}

KEY WORDS: Carcinoma. Caecum. Intussusception. Intestine. Obstruction. Hemicolectomy.

\section{INTRODUCTION}

Carcinoma of colon and rectum rank second only to malignant lung tumour in incidence and death rate. An estimated 150,000 new cases and 17,000 deaths occur annually in United Kingdom from this disease ${ }^{1}$. Carcinoma of colon specially right colon is more common in women while carcinoma of rectum is more common in males. Seventy-five percent of carcinoma of colon occurs in left colon, $22 \%$ in right colon and caecum has a share of $03 \%$ only ${ }^{2}$. The right colon has large caliber and a thin and distensible wall, and the faecal content is fluid. Because of these anatomic features, carcinoma of right colon may attain a large size before it is diagnosed ${ }^{3}$. Patient of carcinoma of caecum often comes to doctor with fatigability and weakness, unexplained microcytic hypochromic anaemia or vague right abdominal discomfort. But, in $10 \%$ of cases presentation may be a mass in right iliac fossa ${ }^{3}$. Here, we report a case of carcinoma of caecum who presented in an unusual way of mega intussusception and a rectal mass.

\section{CASE REPORT}

A 45 years old male resident of Mirpurkhas District landed in emergency room with signs and symptoms of acute abdomen. He also complained of pain in lower abdomen for last 2 months, distension of abdomen and diarrhea for one month, and low-grade fever for one month. On his arrival, he was seriously ill, dehydrated with sunken eyes, pulse rate was 120/ minutes (low volume), blood pressure was (80/50 $\mathrm{mmHg}$ ) and temperature $\left(100^{\circ} \mathrm{F}\right)$. He also had distended tender abdomen with absent bowel sounds. Digital rectal examination revealed mass in rectum, which was extremely tender. An emergency laparotomy was decided and after resuscitation for six hours, laparotomy was performed. On exploration, a mega intussusception involving ileum, caecum, ascending, transverse, descending and sigmoid colon; all packed in rectum was found. Hot packs were applied and reduction tried. But, it was not possible to reduce except up to mid transverse colon. So, an extended right hemicolectomy was done (Figure I). End to end anastomosis between ileum and transverse colon was made in two layers (Figure II). On gross examination of resected segment, a fungating growth was seen in the caecum. Liver, mesenteric lymph nodes and rest of abdominal cavity were normal. Abdomen was closed after putting a drain. Postoperative phase was smooth with reappearance of bowel sounds on $3^{\text {rd }}$ postoperative day and flatus on $4^{\text {th }}$ day. Liquids and later on semi-solids were allowed. Because of minor wound infection patient was kept admitted for few more days and he was discharged on $11^{\text {th }}$ postoperative day. On followup visit on $25^{\text {th }}$ postoperative day, he was healthy with normal meals and bowels. His biopsy report showed well differentiated adenocarcinoma of caecum involving muscularis but serosa was spared. Then, he was referred to department of nuclear medicine for chemotherapy.

FIGURE I:

\section{RESECTED SEGMENT OF GUT HAVING} INTUSSUSCEPTION ALONG WITH

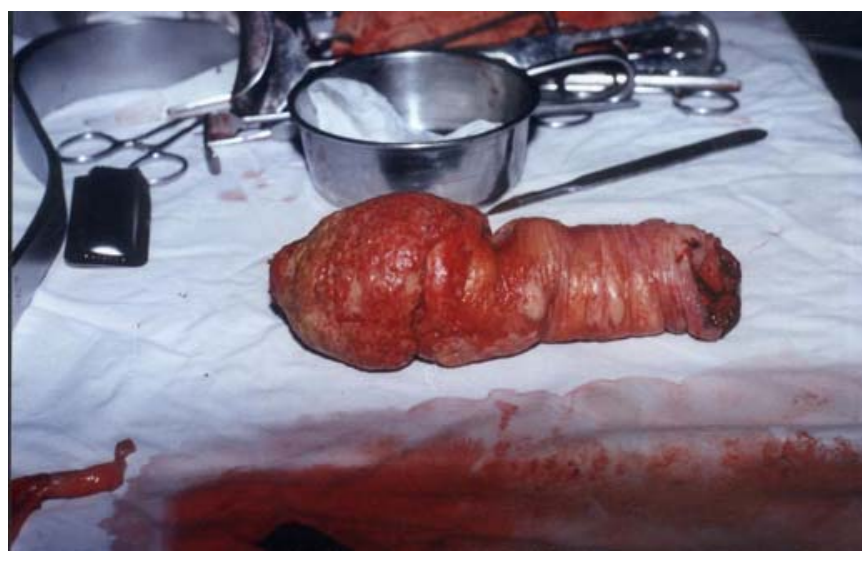




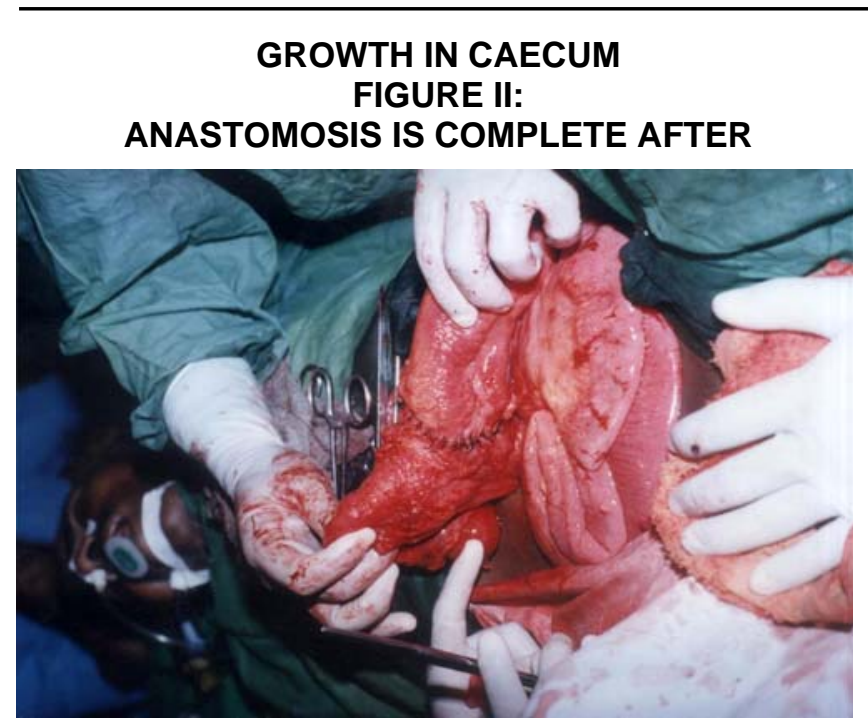

\section{DISCUSSION}

RESECTION

Carcinoma of colon causes about 17,000 deaths annually in UK. While in USA about 60,000 people die of this disease each year ${ }^{1}$. The worldwide frequency of this disease is related to a high degree of industrialization and socioeconomic standards. Incidence is high in rectum and sigmoid colon. Only $5 \%$ of patients suffer multiple synchronous colonic cancers that is two or more carcinomas occurring simultaneously ${ }^{2}$. Metachronous cancer, a new primary lesion in a patient who had a previous resection for cancer has an incidence of about $2 \%$. Genetic, ulcerative colitis, crohn's disease, schistosomal colitis, radiation, colorectal polyps and ureteric diversion in colon are considered as predisposing factors. Grossly colorectal cancers can take several distinctive appearances ${ }^{4}$. Colorectal cancer can be rather insidious in its presentation and sometimes its early symptoms may be dismissed by patient and physician alike. Even, sinister manifestations like rectal bleeding have frequently been attributed to benign cause such as haemorrhoids ${ }^{5}$. However, sigmoid and rectal lesions have the most classic symptomatology. Rectal bleeding is the most frequent presentation and is usually slight. Some recent alteration in bowel habit, usually in the form of increasing constipation alternating with diarrhea is significant. The later is known as spurious morning diarrhea, which is merely a discharge of mucous in the presence of actual constipation. Tenesmus is particularly prominent with rectal lesion ${ }^{6}$. Fatigability and weakness due to anaemia are often main symptoms, with later addition of vague right abdominal discomfort. Therefore, most of the time patient receives treatment for a gall bladder disease or gastritis ${ }^{7}$. Surprisingly, bowel habits are not altered and obstruction may be a feature when disease is advancing. In only $10 \%$ of cases, a mass is a presenting feature. For diagnosis, no laboratory investigation is reliable, even elevated serum carcino-embryonic antigen (CEA) is not specifically associated with colorectal cancer. However, abnormally high levels of CEA are also found in sera of patients with other gastrointestinal cancers (stomach, liver etc.) ${ }^{8}$. On imaging studies through barium enema examination, lesions of the right colon may appear as a constriction or an intramural mass. The bowel wall is inflexible at the site of lesion and the mucosal pattern is destroyed ${ }^{1}$. This is a picture of locally advance carcinoma. Earlier stage of the disease produce less characteristic filling defects and should be investigated with colonoscopy ${ }^{9}$ and biopsy. However, Spiral Hydro CT $\operatorname{Scan}^{10}$ and $\mathrm{MRI}^{11}$ are helpful in assessing extra mural extension. Treatment consists of surgical resection of the tumour and its regional lymphatic drainage. The primary lesion is resected, even if distant metastases have occurred, since prevention of obstruction or bleeding may offer palliation for long period ${ }^{11}$. The role of adjuvant radiation therapy is controversial. Combination therapy with intravenous 5-fluorouracil $\left(1,000 \mathrm{mg} / \mathrm{m}^{2}\right)$ and oral levomisole has excited recent interest $^{11}$.

In conclusion, presenting features of carcinoma of caecum in early stage are non-specific. However, any complication $^{12}$ that develops in relation to early carcinoma can be blessing for the patient as it draws attention when resection is curative.

\section{REFERENCES}

1. Bolin S, Franzen L, Nilsson E et al. Carcinoma of colon and rectum: tumours missed by radiologic examination in 61 patients. Cancer 1988; 61: 1999-2008.

2. Golematis BC, Tzardis PJ, Al Ahwal J et al . Site distribution of carcinoma of the large intestine: Retrospective study of 600 cases. Dis Colon Rectum 1989; 32: 14-16.

3. Ghahremani GG, Donlatshahi K. Colorectal carcinoma: Diagnostic implication of their changing frequency and anatomic distribution. World J Surg 1989; 13: 321.

4. Grossman S, Milos ML. Colonoscopic screening of persons with suspected risk factors for colon cancer. Family history. Gastroenterology 1988; 94: 395.

5. Kune GA, Kune S, Watson LF. The role of heredity in the etiology of large bowel cancers. Data from the Melbourne colorectal cancer study. World J Surg 1989; 13: 124. 
6. Adell R, Marcote E, Segarra MA et al. Is mucinous colorectal adenocarcinoma a distinct entity? Gastroenterol Hepatol Spain 2000;25 (9): 534-40.

7. Harris GJ, Church JM, Senagure AJ et al. Factors affecting local recurrence of colonic adenocarcinoma. Dis Colon Rectum 2002; 45 (8): 1029-34.

8. Moore M, Jones DJ, Schofield PF et al. Current status of tumor markers in large bowel cancer World J Surg 1989; 13: 52 - 9.
9. Longo WE, Ballantyne $\mathrm{GH}$, Modlin IM. Colonoscopy detection of early colorectal cancers: Impact of a surgical endoscopy service. Ann Surg 1988; 207: 147.

10. Cademartiri F, Luccichenti G, Rossi A et al. Spiral Hydro-CT in the evaluation of Colo-Sigmoidal cancer. Radio Med (Torin) Italy 2002;104 (4):295306.

11. Shimizu J, Masutani S, Ishida $\mathrm{H}$ et al. A case of spinal infarction related to hepatic arterial infusion chemotherapy. Gan To Kagaku Ryoho Japan

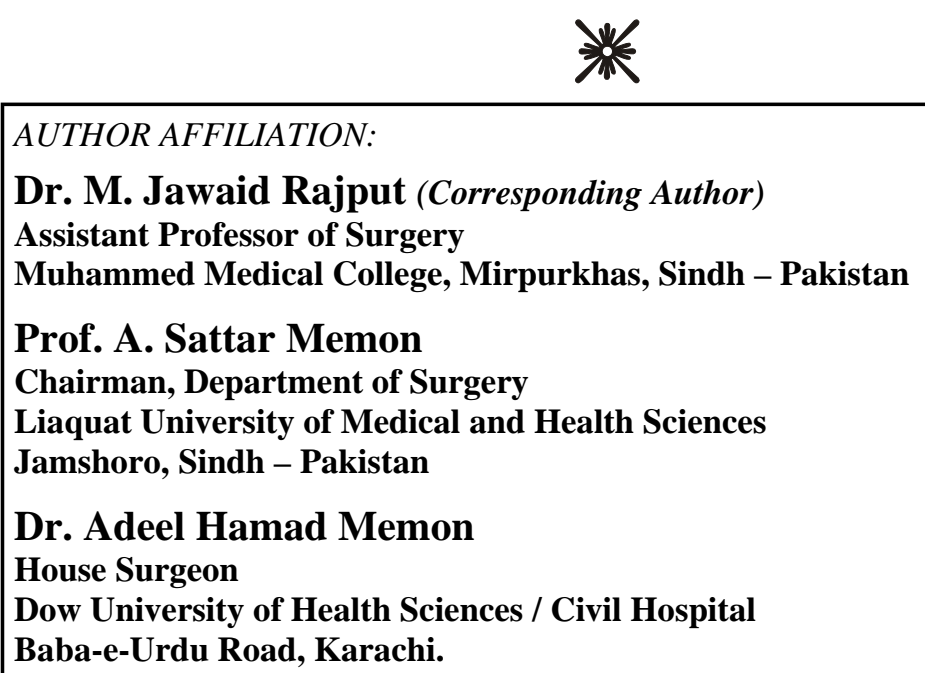

